\title{
USING QUERCUS INFECTORIA GALL NUT TANNIN AS A BINDER IN PARTICLEBOARDS PRODUCTION
}

\author{
Walid A. Kasir
}

Dept. of Forestry, College of Agric. and Forestry, Mosul Univ., Iraq

\begin{abstract}
Adhesives derived from oak (Quercus infectoria) galls tannin and ureaformaldehyde were used to produce particleboards of $18 \mathrm{~mm}$. thickness from pinewood particles at 8 and $12 \%$ resin content and target density of $0.60 \mathrm{gm} /$ $\mathrm{cm}^{3}$. Five levels of blending ratios were followed namely; $100 \mathrm{TF}: 0 \mathrm{UF}, 75$ TF:25 UF, 50 TF:50 UF, 25 TF:75 UF, and O TF:100 UF. The physical and mechanical properties of the produced panels were tested after conditioning according to ASTM standard D-1073. The results indicated, that tannin from oak galls has good potential for use as adhesive. It has been shown from the results that incorporating urea-formaldehyde with tannin-formaldehyde produced good quality adhesive for the manufacture of particleboard for interior use. An increase in the levels of urea in the adhesive blends caused an increase in panels strength such as MOR, MOE, and IB, while WA and Th.S. decreased by increasing levels of tannin-formaldehyde. The increase in resin content of all produced panels improved all particleboard properties.
\end{abstract}

\section{INTRODUCTION}

In the recent past, increasing attention has been paid to the use of natural adhesives as a binder in the wood-based panels industry. The idea of developing adhesives based on tannin-formaldehyde resins dated back for more than 40 years (Dalton, 1950, 1953; Naryanamurti et al., 1957, 1958; Plomley et al., 1957, 1964). However, almost unlimited availability of cheap oil-based binders has considerably delayed the development of these resin systems. Only the cut-back and the increase in the price of oil-based binders in the seventies have activated the interest in tannins as a materials derived from suitable resources.

In 1971, an unfortified mimosa tannin adhesive for particleboard was formulated, which is one substantially in it's present form that has dominated the field of industrial tannin-based adhesives (Pizzi, 1977 and 1989). Several other tannin adhesive formulations to manufacture particleboard, all with good results, but all these are obtained by addition of fortifying synthetic resins such as urea-formaldehyde and phenol-formaldehyde (Pizzi, 1978).

In Iraq, research into the use of eucalyptus bark tannin started in the early years of 2002. Al-Zaidbagy (2002) reported that the tannin content of Eucalyptus cammaldulensis compared quite favorably with that of known commercial tannin sources and good properties of particleboard panels were produced from such source of tannin. Among the most common mountain forest communities in North of Iraq regions are the endemic oak species of gall oak (Quercus infectoria Oliv.) and volonia oak (Q. aegilops L.).

Received 16/1/2005 accepted 10/5/2006 
Gall oak is a small or medium size tree grown frequently on the more favorable sites of ranges $800-1500 \mathrm{~m}$. above sea level. High content gall nuts are collected annually for exporting purposes or for using in local

leather industries. Mohammad et al. (1988 and 1999) indicated as the results of their survey and chemical analysis, the presence of twenty types of gall wasps on oak trees which causes afus galls contained different amount of tannic acid. Only four species of wasps namely; Andricus gallaetinctoria Ol., A. hartigi Hart., Aphelonyx cerricola Gir., And Andricus insana Mayer., are commercially important. The galls are sufficiently large and contain large amounts of tannic acid (45-65\% based on dry weight of the sample). The percentage of tannins varies depending on oak tree species, age of trees, location, and wasp species. No work has been experienced in Iraq concerning the use of oak galls tannin in particleboard manufacturing, therefore, the objectives of this study were to:

1- Compare the strength and dimensional properties of particleboards bonded with oak galls tannin-formaldehyde with commercial synthetic ureaformaldehyde.

2- Determine the effect of partial replacements of galls tannin with ureaformaldehyde and the percent of resin content on properties of panels

\section{MATERIALS AND METHODS}

Quercus infectoria gall nuts were collected from trees growing in the northern part of Iraq (Duhok provience). The gall nuts tannin was obtained as a liquid extract after extraction from $Q$. infectoria gall nuts with hot water maintained at 60-70 $\mathrm{c}^{\circ}$, using the counter-current method. The tannin extract was concentrated to $50 \%$ solid content and treated with $10 \%$ ( based on oven dry weight ) para-formaldehyde. The urea-formaldehyde as a commercial adhesive was obtained from Mosul furniture factory as a powder, the liquid urea was prepared by dissolving the urea in water. The liquid urea contained 50 $\%$ solid. The mixed ratios of tannin-paraformaldehyde ( $\mathrm{TF}$ ) and ureaformaldehyde ( UF ) were prepared for particleboard studies as follows: 100 TF:0 UF (A), 75 TF:25 UF (B), 50 TF:50 UF (C), 25 TF:75 UF (D), 0 TF:100 UF (E), by dry weight of the adhesives.

Homogenous panels of dimensions of $35^{*} 35^{*} 1.8 \mathrm{~cm}$. were produced at targeted density of $0.60 \mathrm{gm} / \mathrm{cm}^{3}$ and two resin contents of 8 and 12 percent based on the oven dry weight of the wood particles ( pine wood, Pinus brutia Ten. ) was used for obtaining the wood chips (The chips were approximately $1.5,0.5$ in length and width respectively with random thickness) for making the panels. The panels were pressed at $175 \mathrm{c}^{\circ}$. for 10 minutes in a singleopening laboratory hot press.

The particleboard panels were sampled and evaluated for the modulus of rupture MOR), modulus of elasticity (MOE), internal bond (IB), thickness swelling (Th.S) and water absorption (WA) according to American standard D1073. The dimensional stability and water absorption were carried out by soaking the samples in water at $20 \mathrm{c}^{\circ}$. for 24 hours. The testing of the samples was carried out after conditioning at $21 \pm 2 \mathrm{c}^{\circ}$ and 65 percent relative humidity. 
The evaluation of the significant differences among the strength and dimensional properties of particleboard panels bonded with different ratios of TF and UF and different levels of resin content was done by the statistical analysis system (SAS) computer package. The values given in tables are the means of six samples (each treatment replicated three times and two samples were taken from each replication).

\section{RESULTS AND DISCUSSION}

Static Bending Properties: The results of the analysis of variance for modulus of rupture (MOR) showed, that there is a high statistical significance (at $1 \%$ level) differences between the strength values obtained when testing the different ratios of tannin-formaldehyde : urea-formaldehyde, also the analysis showed a significant effect of the levels of resin content on this property (table $1)$.

In the average values of ratios of TF : UF of table 2 , it is noticed that all ratios used in manufacturing panels at both levels of resin content resulted in an MOR values exceeded the minimum MOR requirements of the interior type boards of commercial American standard 66-CS 236. Panels made from 0 TF:100 UF (E) gave the highest MOR value of $163.75 \mathrm{~kg} / \mathrm{cm}^{2}$., followed by panels (D) manufactured from $25 \mathrm{TF}: 75 \mathrm{UF}$, with an MOR value of $153.35 \mathrm{~kg}$ / $\mathrm{cm}^{2}$., while panels (A) which were made from 100 TF:0 UF had the lowest MOR $121.45 \mathrm{~kg} / \mathrm{cm}^{2}$.. It seems from figure 1 , that there is an increase in the values of MOR with an increase in the percentages of UF in the panels.

With regard to the effect of resin content, it is evident from table 2 and figure 1, that as the resin content increased from 8 to $12 \%$, MOR increased from 137.14 to $154.34 \mathrm{~kg} / \mathrm{cm}^{2}$. These results are in line with those obtained by Teck et al. (1993), who also found an increase in MOR with the increase in resin content in panels manufactured from rubber wood particles bonded with mangrove tannin extracted from mangrove bark by hot water.

Table 1. Analysis of variance for particleboard properties.

\begin{tabular}{|c|c|c|c|c|c|c|}
\hline \multicolumn{2}{|c|}{$\begin{array}{c}\text { Sources } \\
\text { D.F. }\end{array}$} & \multicolumn{5}{|c|}{ Mean Squares } \\
\cline { 3 - 7 } & MOR & MOE & IB & Th.S. & WA \\
\hline Block & 2 & 657.33 & 4973769.2 & 0.60 & 94.03 & 3.00 \\
\hline A & 1 & $2153.24^{* *}$ & $216121048.0^{* *}$ & $14.57^{* *}$ & $315.57^{* *}$ & $975.84^{* *}$ \\
\hline B & 4 & $1553.65^{* *}$ & $12567708.2^{*}$ & $4.71^{* *}$ & $81.04^{* *}$ & $244.56^{*}$ \\
\hline AB & 4 & $18.225^{\text {n.s }}$ & $542120.0^{\text {n.s }}$ & $0.96^{*}$ & $2.39^{\text {n.s }}$ & $3.62^{\text {n.s }}$ \\
\hline Error & 18 & 135.18 & 2689329.4 & 0.27 & 7.99 & 73.84 \\
\hline
\end{tabular}

** significant at the $1 \%$ level., $*$ significant at the $5 \%$ level., ns not significant. $\mathrm{A}=$ resin content $, \mathrm{B}=\mathrm{TF}: \mathrm{UF}$ ratios.

With respect, to modulus of elasticity (MOE): Table 1 shows, that there is a significant effect (at 5\% level) of ratios of TF: UF on MOE values obtained when testing the different ratios. It is evident from Duncan's multiple range test (table 2) that the highest values of MOE regardless the levels of resin content obtained (20593 kg / $\mathrm{cm}^{2}$.) from panels E (0 TF:100 UF) and the lowest (16909 
$\mathrm{kg} / \mathrm{cm}^{2}$.) from panels A (100 TF:0 UF), while the values of MOE of the other ratios located between $\mathrm{A}$ and $\mathrm{E}$, i.e, it appeared as figure 2 shows, that there is a decrease in MOE values as the amount of tannin-formaldehyde increases in the ratios. It can further be noticed from Duncan's table, that there was no significant differences in MOE between A (100 TF:0 UF), B (75 TF:25 UF) and C (50 TF:50 UF). Similar results concerning MOR and MOE values were obtained by Kasir and Al-Zaidbagy (2004) in their study on the utilization of Eucalyptus cammaldulensis bark extract fortified with UF and Goncalves et al. (2003) in their study on particleboard made with UF modified with tannin from mimosa (Mimosa caesalpiniaefolia Bentham). Both found a decrease in MOE with an increase in tannin extract in glue mix.

Table 2. Averages of physical and mechanical properties of particleboards.

\begin{tabular}{|c|c|c|c|c|c|c|}
\hline \multirow{3}{*}{ R.content (\%) } & \multicolumn{6}{|c|}{ TF:UF Ratios } \\
\hline & A & B & $\mathrm{C}$ & $\mathrm{D}$ & $\mathrm{E}$ & Ratios Avg \\
\hline & \multicolumn{6}{|c|}{$\operatorname{MOR}\left(\mathrm{kg} / \mathrm{cm}^{2}\right)$} \\
\hline 8 & 114.2 & 131.5 & 142.7 & 145.1 & 152.7 & 137.14B \\
\hline 12 & 128.7 & 147.0 & 159.1 & 161.6 & 175.3 & $154.34 \mathrm{~A}$ \\
\hline \multirow[t]{2}{*}{ Resin Avg. } & $121.45 \mathrm{c}$ & $139.25 \mathrm{bc}$ & $150.90 \mathrm{ab}$ & $153.35 \mathrm{ab}$ & $163.75 \mathrm{a}$ & \\
\hline & \multicolumn{6}{|c|}{$\operatorname{MOE}\left(\mathrm{kg} / \mathrm{cm}^{2}\right)$} \\
\hline 8 & 14486 & 14654 & 15980 & 16110 & 17420 & 15730B \\
\hline 12 & 19333 & 19981 & 20880 & 21532 & 23765 & $21098 \mathrm{~A}$ \\
\hline \multirow[t]{2}{*}{ Resin Avg. } & $16909 \mathrm{~b}$ & $17318 b$ & $18430 \mathrm{~b}$ & $18821 \mathrm{ab}$ & $20593 a$ & \\
\hline & \multicolumn{6}{|c|}{ IB $\left(\mathrm{kg} / \mathrm{cm}^{2}\right)$} \\
\hline 8 & $3.90 \mathrm{c}$ & $3.98 \mathrm{c}$ & $4.85 \mathrm{c}$ & $4.65 c$ & $4.96 \mathrm{c}$ & $4.46 \mathrm{~B}$ \\
\hline 12 & $4.43 \mathrm{c}$ & $4.66 \mathrm{c}$ & $6.20 \mathrm{~b}$ & $6.81 \mathrm{ab}$ & $7.21 \mathrm{a}$ & $5.86 \mathrm{~A}$ \\
\hline \multirow[t]{2}{*}{ Resin Avg. } & $4.16 \mathrm{~b}$ & $4.32 \mathrm{~b}$ & $5.52 \mathrm{ab}$ & $5.73 \mathrm{ab}$ & $6.08 \mathrm{a}$ & \\
\hline & \multicolumn{6}{|c|}{ Th.S. (\%) } \\
\hline 8 & 17.6 & 20.5 & 19.7 & 23.2 & 25.7 & $21.34 \mathrm{~A}$ \\
\hline 12 & 11.3 & 11.1 & 12.3 & 18.7 & 19.2 & $14.52 \mathrm{~B}$ \\
\hline \multirow[t]{2}{*}{ Resin Avg. } & $14.45 \mathrm{~b}$ & $15.80 \mathrm{~b}$ & $16.00 \mathrm{~b}$ & $20.91 \mathrm{a}$ & $22.40 \mathrm{a}$ & \\
\hline & \multicolumn{6}{|c|}{ WA (\%) } \\
\hline 8 & 38.2 & 44.6 & 43.9 & 51.8 & 55.8 & $46.86 \mathrm{~A}$ \\
\hline 12 & 27.7 & 35.3 & 32.5 & 38.7 & 43.1 & $35.46 \mathrm{~B}$ \\
\hline Resin Avg. & $32.95 \mathrm{c}$ & $39.95 b c$ & $38.20 b c$ & $45.25 \mathrm{ab}$ & $49.45 \mathrm{a}$ & \\
\hline
\end{tabular}

$\mathrm{A}=100 \mathrm{TF}: 0 \mathrm{UF}, \mathrm{B}=75 \mathrm{TF}: 25 \mathrm{UF}, \mathrm{C}=50 \mathrm{TF}: 50 \mathrm{UF}, \mathrm{D}=25 \mathrm{TF}: 75 \mathrm{UF}, \mathrm{E}=0 \mathrm{TF}: 100$ UF.

Averages followed by the same letter are not significantly different at $\mathrm{P}<0.05$.

Concerning the effect of resin content on MOE, analysis of variance showed a significant effect (at $5 \%$ level) of this factor on MOE. Table 2 shows a great increase in MOE (from 15730 to $21098 \mathrm{~kg} / \mathrm{cm}^{2}$.) as the level of resin content increased from 8 to $12 \%$, this increase was clear in the whole ratios, which reflect the need for more resin in the board to get better values of this property. Again this result is in agreement with that obtained by Teck et al. (1993). 
In general, the average MOE values for all panels produced at 8 and $12 \%$ resin content exceeded the lower value given by American standard 66-CS 236 for interior panels, and the values enhanced with the increase in the amount of UF in the blends.

Internal Bonds (IB): The results of variance analysis for internal bond showed, that the ratio of TF:UF and resin content as a main factors were significant (at 1\%level) in their effects on IB, while the effect of their interaction appeared to have significant effect (at 5\% level) on this property. In the average ratios of TF:UF, analysis of table 2 and from figure 3, it appeared that the highest values of IB $\left(6.08 \mathrm{~kg} / \mathrm{cm}^{2}\right)$ obtained from panels E $(0 \mathrm{TF}: 100$ UF) followed by panels D (25 TF:75 UF) which had a value of $\left(5.73 \mathrm{~kg} / \mathrm{cm}^{2}\right)$ and the later did not differ from $\mathrm{C}\left(5.52 \mathrm{~kg} / \mathrm{cm}^{2}\right)$ as Duncan's shows, while the lowest value $\left(4.16 \mathrm{~kg} / \mathrm{cm}^{2}\right)$ obtained from panels A (100 TF:0 UF). It appeared that reinforcing the adhesive mixtures with urea improved the values of IB in the same way as in case of MOR and MOE.

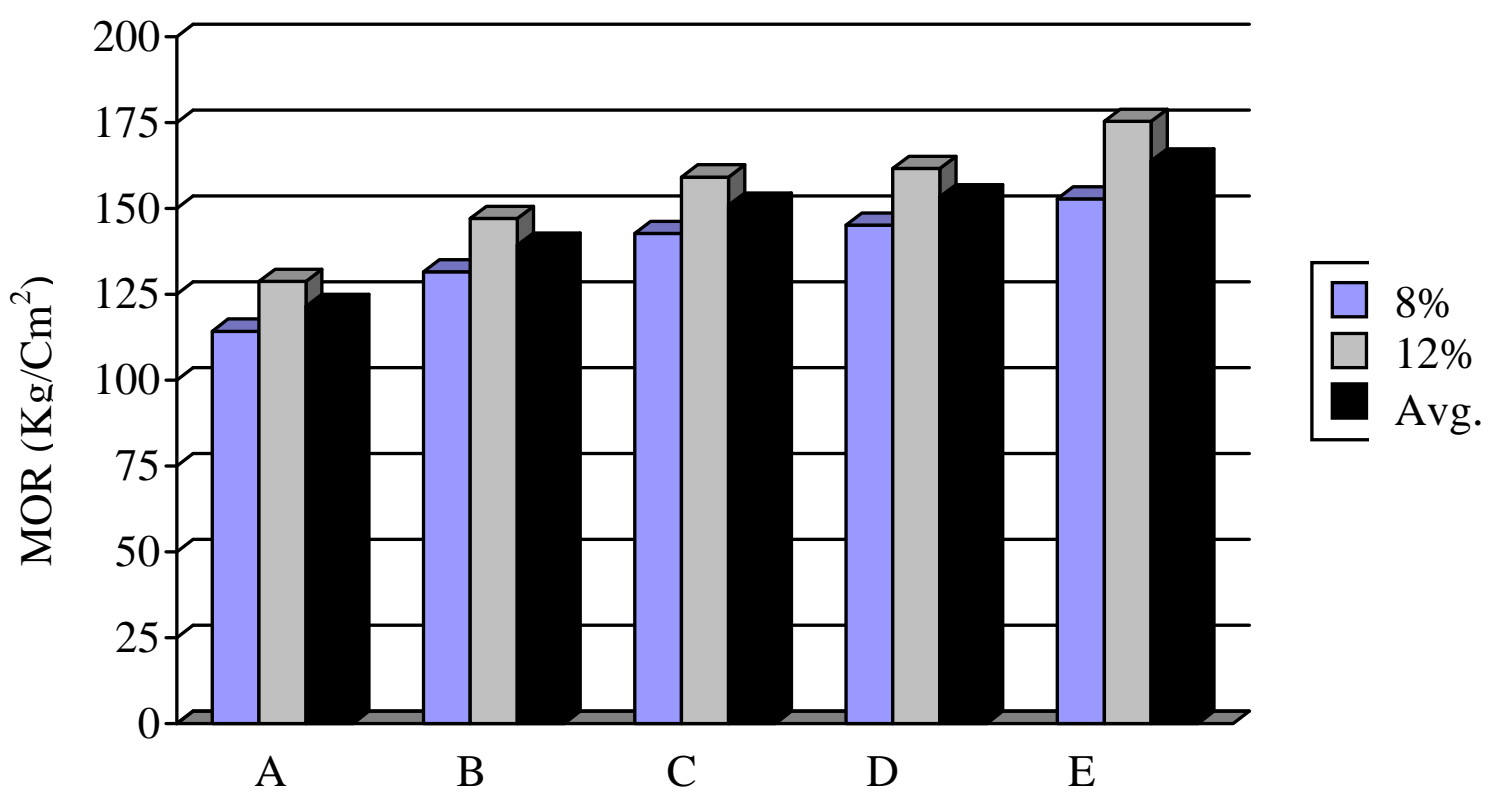

Ratios of TF : UF

Fig. 1: Influence of ratios of tannin-formaldehyde to urea-formaldehyde at 8 and $12 \%$ resin content on modulus of rupture of panels. 


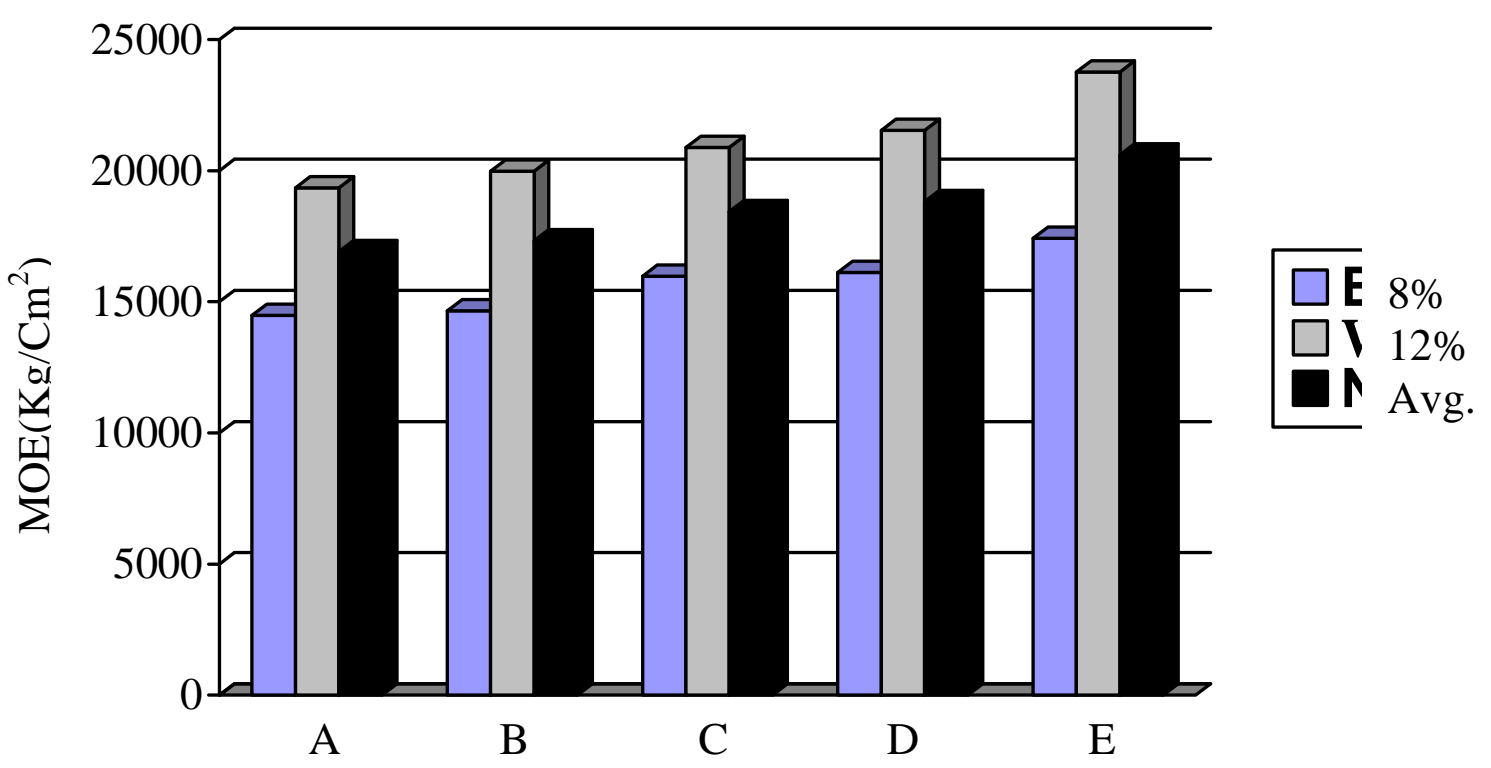

Ratios of TF : UF

Fig. 2: Influence of ratios of tannin-formaldehyde to urea-formaldehyde at 8 and $12 \%$ resin content on modulus of elasticity of panels

Generally speaking, all the treatment combinations gave high values of IB and all the values appeared to be close or a little higher than the minimum values of American standard for interior type panels, this may be attributed to the use of high platen temperature $\left(175^{\circ} \mathrm{C}\right)$ and long pressing time during hot pressing, such conditions probably enhanced the polymerization and curing of the adhesive. Similar results reported by Sumadiwangsa (1985) who studied the use of mangrove (Rhizophora mucronata) bark tannin as a powder added directly to the chips, he stated, that there was a linear correlation between temperature and various properties of particleboards, the higher the temperature the better the quality of the boards.

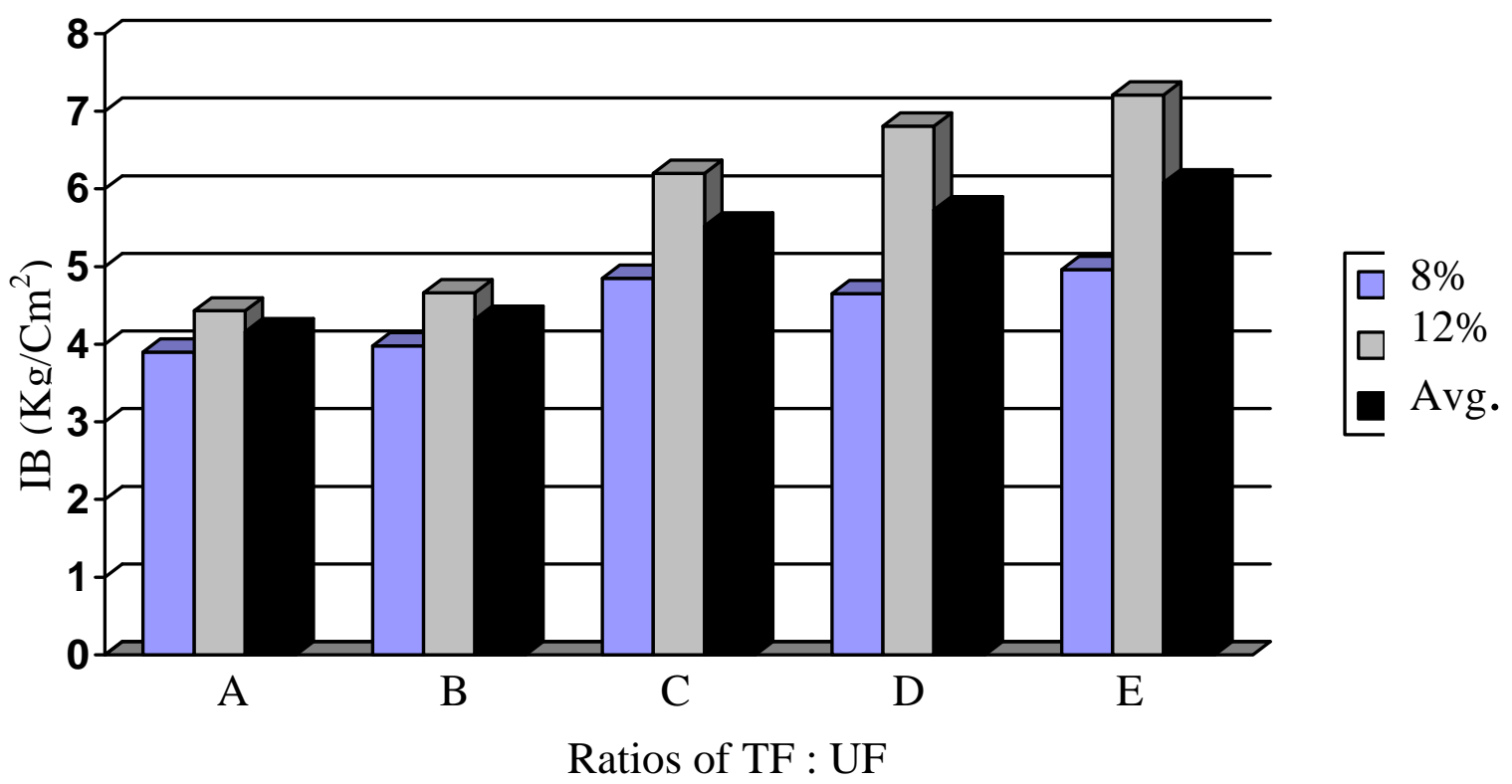


Fig. 3: Influence of ratios of tannin-formaldehyde to urea-formaldehyde at 8 and $12 \%$ resin content on internal bond of panels.

With respect to resin content, it is shown (table 2 and figure 3), that panels made at $12 \%$ target resin content were significantly better in internal bond than these made at $8 \%$ resin content. The averages were 4.46 and $5.86 \mathrm{~kg}$ $/ \mathrm{cm}^{2}$ for 8 and $12 \%$ respectively. The result is in conformance with Teck et al. (1993) who also found, direct relationship between internal bond and different levels of resin content (tannin-urea formaldehyde was used among different types of adhesives tested in their study).

Thickness Swelling After 24 Hours Immersion (Th.S.):The results of variance analysis for thickness swelling (table 1) show, that adhesive ratios along with the level of resin content had significant effect (at $1 \%$ level) on this property. It appeared that the lowest value (14.45\%) of thickness swelling (table 2) was noticed in panels produced from $100 \mathrm{TF}: 0 \mathrm{UF}$, and this value in turn did not differ statistically from panels B (75 TF:25 UF) and C (50 TF:50 UF) as shown in Duncan's table, the average values were 15.80 and $16.00 \%$ for $\mathrm{B}$ and $\mathrm{C}$ respectively, and the highest value $(22.40 \%)$ was noticed in panels $\mathrm{E}$ (0 TF:100 UF) and this in turn did not differ from panels D (25 TF:75 UF) which gave an average of thickness swelling equal to $20.91 \%$. It seems from the results that by reinforcing the tannin mix with urea, the thickness as a property affected negatively. This may be due to the interference in the curing of the adhesive as explained by Gokay et al. (2003), who stated that bark extract decreases the thickness swelling of particleboards, and that is due to the high amount of polyphenolic extractives in the bark. Polyphnolic extractives can react with formaldehyde even at normal temperature to yield condensation products with high bonding potential, for this reason, the water diffusion and absorption could be decreased, and also probably due to a decrease in the resistance of UF for water in case of immersion for 24 hours.

With regards to the effect of resin content on thickness swelling, it is found from table 2 and figure 4, that panels made at $12 \%$ target resin content were significantly better in thickness swelling (14.52\%) than panels made at $8 \%(21.34 \%)$. This result comes in agree with several workers who studied various types of synthetic and natural adhesives and reported a decrease in swelling with increasing percentages of resin content to the limit not exceeding $12 \%$, otherwise, the whole process would be costly (Halligan and Schniewind, 1972; Beech, 1975; Shuler, 1975).

When the values of thickness swelling of all panels were compared to the maximum property requirments of American standard, all panels which contained high amount of urea-formaldehyde in the blends of adhesive exceeded $15 \%$ as a maximum allowable value, while the panels with higher amount of tannin-formaldehyde expressed values were more or less within the specification. 


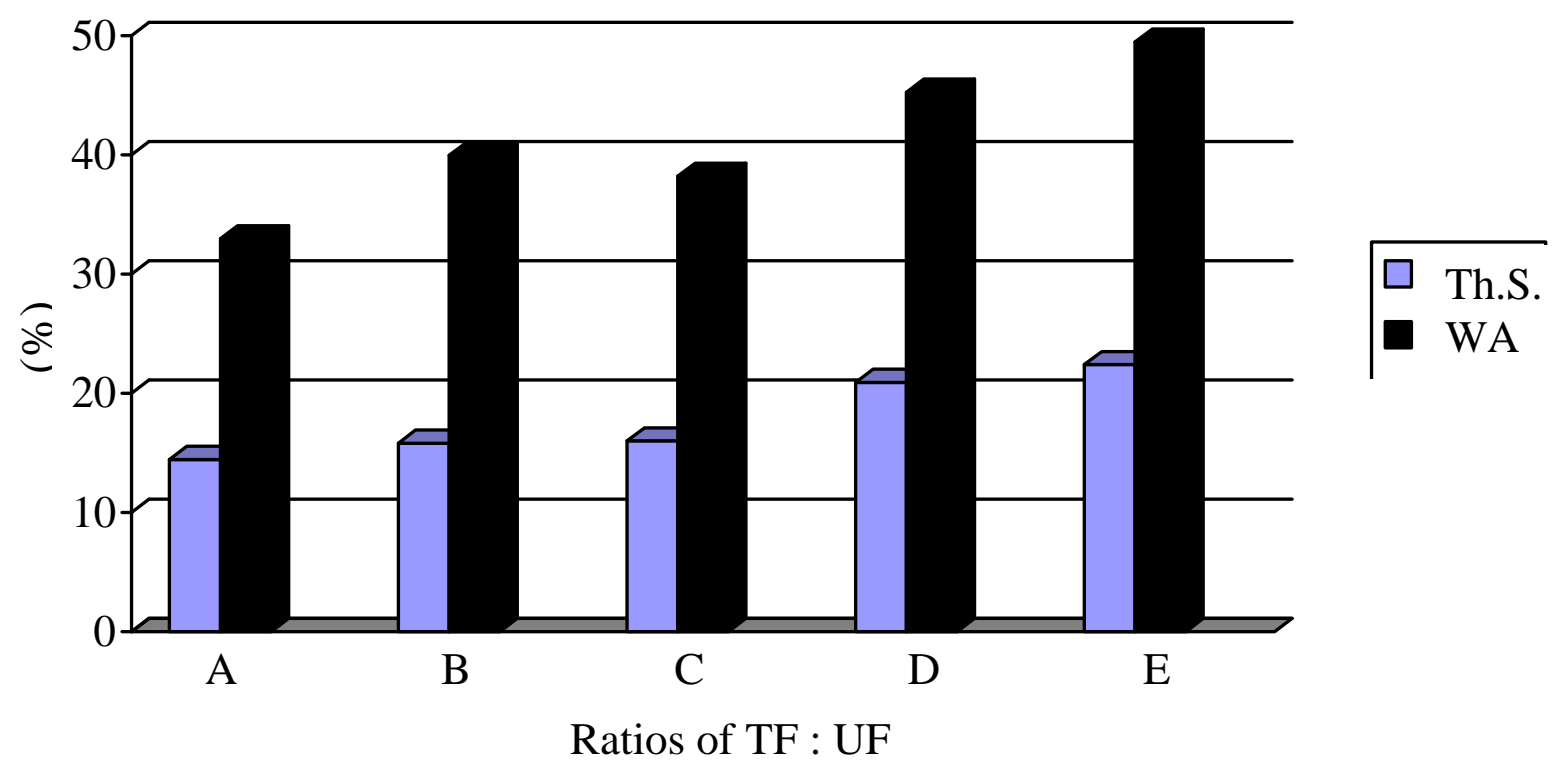

Fig. 4: Influence of ratios of tannin-formaldehyde to urea-formaldehyde on thickness swelling and water absorption of panels.

Water Absorption after 24 Hours Immersion (WA): Concerning water absorption after $24 \mathrm{hr}$. immersion in water, table 1 shows that there is significant (at 1\% level) between the WA values obtained when testing the different ratios of adhesive blends. It is evident from Duncan's multiple range test (table 2 and figure 4), that the lowest value of WA (32.95\%) obtained from panels A (100 TF:0 UF) which differed significantly from the other panels contained urea in their adhesive blends, and the highest $(49.45 \%)$ from panels E (0 TF:100 UF), while the values of WA of the other adhesive blend ratios located between the two extremes A and E, i.e, it appeared that there is a decrease in WA as the percentage of TF increases in the blends of adhesive. This decrease is probably due to the formation of condensation products with high bonding potential as explained earlier with thickness swelling (Gokay et al., 2003).

Regarding, the effect of resin content on WA, analysis of variance showed, a significant effect (at 5\% level) of this factor on this property, table 2 shows a clear decrease in WA (from 46.86 to $35.46 \%$ ) as the resin content increased from 8 to $12 \%$. This decrease is in line with what was noticed by Shuler (1975) and Teck et al. (1993) in their studies concerning the effects of resin content on the properties of particleboards.

In general, the results of this study have shown that tannin from oak galls has good potential for use as adhesive. Research has proved that, incorporating urea-formaldehyde with tannin-formaldehyde produced goodquality adhesive for manufacturing particleboard for interior use. An increase in the levels of urea-formaldehyde in the adhesive blends caused an increase in panels strength such as MOR, MOE, and IB, while WA and TS decreased with the increasing levels of TF. The increase in resin content of all produced panels improved all particleboard properties. 


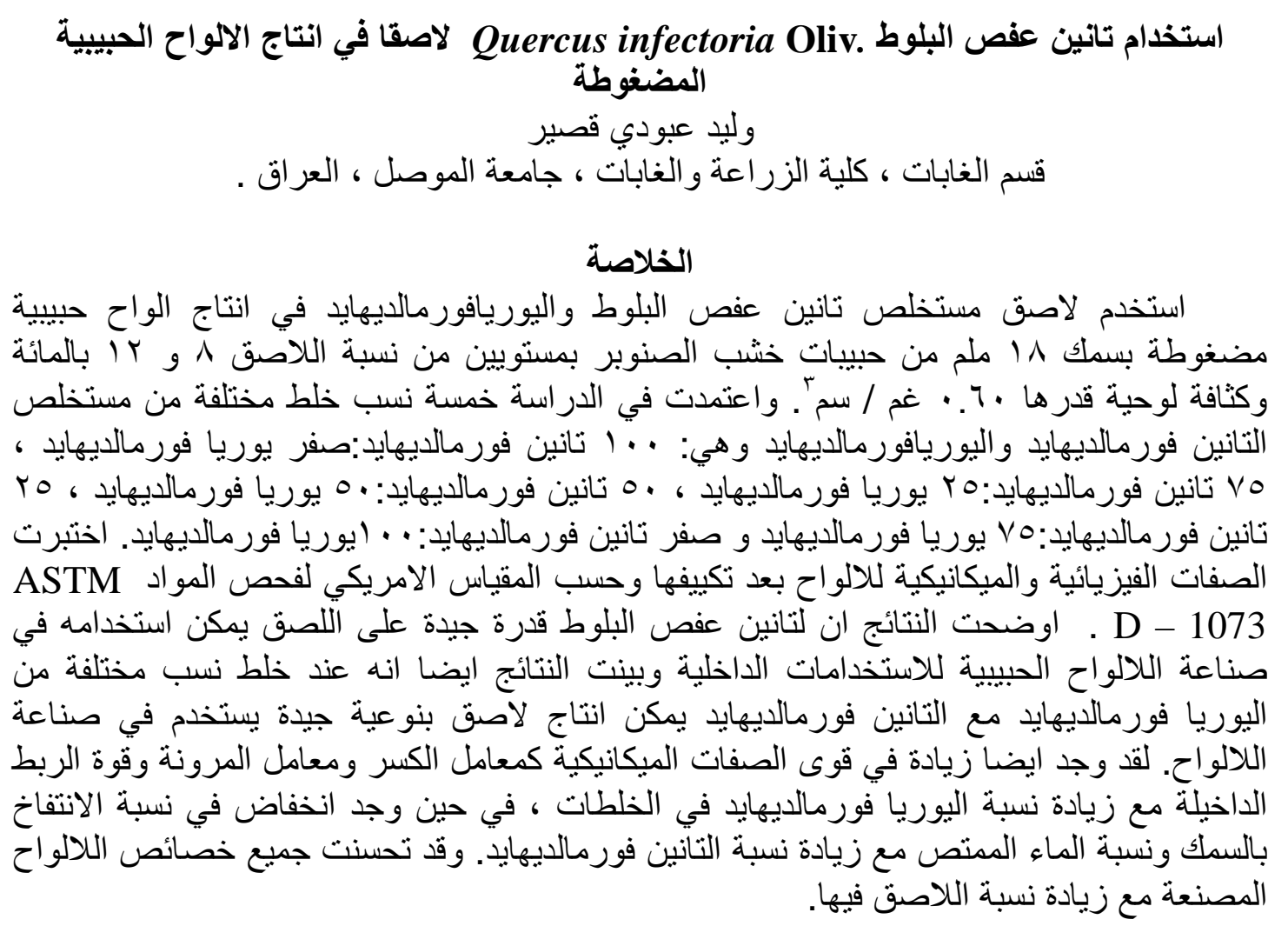

\section{REFERENCES}

Al-Zaidbagy, O. I. (2002). Utilization of Eucalyptus cammaldulensis bark extract as an Adhesive for particleboards. Ph.D. Thesis, College of Agric. \& Forestry, Mosul University, Iraq.

ANSI standard. 66 - CS 236. American specifications for interior type particle bords.

ASTM standard (1998). Standard methods of evaluation of the properties of woodbased Fiber and particle panel materials. Annual book of ASTM standards, ASTM D- 1073-78 B. Philadelphia.

Beech, J. C. (1975). The thickness swelling of wood particleboard. Holzforschung 29(1):11-18.

Dalton, I. K. (1950). Tannin-formaldehyde resins as adhesives for wood. Austr. J. Appl. Sci. . 1:54-70.

Gokay, N.; H. Kirci; A. Temiz (2003). Influence of impregnating wood particles with Mimosa bark extract on some properties of particleboards. Elsevier. An international J. For Industerial Crops and Products, 20:339-344.

Goncalves, C. A.; R. C. Lelis; E. O. Brito (2003). Particleboard made with ureaformal- dehyde modified with tannin from Mimosa caesalpiniaefolia Benthan. Florestae Ambiente, 10(1):18-26.

Halligon, A. F. and A. P. Schniewind (1972). Effect of moisture on physical and creep Properties of particleboard. For. Prod. J. 22(4):13-16.

Kasir, W. A. and O. I. Al-zaidbagy (2004). Improving the properties of particleboard bonded by fortified eucalyptus bark extract with urea-formaldehyde. Iraqi J. For Agric. Sci. 5(4):69-76.

Mohammad, M. A.; B. A. Ahmed; A. H. Amin; R. I. Al-hamdany (1988). Study of morphlogy and chemistry of afus galls produced by some gall wasps on oak trees in northern Iraq. Arabic J. of Plant Protection. 6(2):76-78. 
Mohammad, M. A.; B. A. Ahmed; I. N. Abdulla (1999). Economic important of afus Galls produced by gall wasps on oak trees in northern Iraq. Education and Science Magazine, $37: 14-18$.

Naryanamurti, D.; P. R. Rao; R. Ram (1957). Adhesives from tamarind seed testa tannin. J. Sci. Ind. Research 16b:377-378

Naryanamurti, D.; N. R. Das (1958). Tannin-formaldehyde-Kleber. Kunststoff 48:459- 462.

Pizzi, A. (1977). Chemistry and technology of cold and thermosetting wattle tanninBased wood adhesive. Ph.D. Thesis, Bloemfontein, South Africa. University of the Orange Free State.

Pizzi, A. (1978). Wattle base adhesive for exterior grade particleboards. For. Prod. J., 28(12):42-47.

Pizzi, A. (1989). Research practice with tannin-based adhesive. Symposium Series No. 385. Washington, D. C.: American Chemical Society, 254-270.

Plomely, K. F. (1964). Tannin-formaldehyde adhesives for wood, I. mangrove tannin Adhesives. Austr. J. Appl. Sci., 15:171-182.

Plomely, K. F.; J. W. Gottstein; W. E. Hillis (1957). Tannin-formaldehyde adhesives.CSIRO Astralian Forest Products Newsletter 234, Melbourne.

SAS, (1979). Statistical analysis system. Carry, North Carolina, USA.

Shuler, C. E. (1975). Pilot study of the use of pulpwood chipping residue for producing Particleboard in Maine. Technical Bulletin, Life Sciences and Agric. Experiment Stations. University of Maine No. 67, 24 p.

Sumadiwangsa, S. (1985). Mangrove bark powder as particleboard adhesive. J. Penelitian Hasil Hutan, 2(4):1-7.

Teck, C. L.; N. M. Nasir; P. M. Tahir (2002). Tannin-based adhesives for rubberwood particleboard. In: Adhesives Technology and Bonded Tropical Wood Products. Chung-Yun Hse, ed. Taiwan Forestry Research Institute, Taipei, Taiwan, ROC. Pp. 28-34. 